\title{
Diferimento de pastos de Brachiaria decumbens adubados com nitrogênio no início e no final do período das águas
}

\author{
Fábio Andrade Teixeira ${ }^{1}$, Paulo Bonomo ${ }^{1}$, Aureliano José Vieira Pires ${ }^{2}$, Fabiano Ferreira \\ Silva ${ }^{2}$, Raul Castro Carriello Rosa ${ }^{2}$, Paulo Valter Nunes Nascimento ${ }^{1}$ \\ 1 Departamento de Estudos Básicos e Instrumentais - Universidade Estadual do Sudoeste da Bahia. \\ 2 Departamento de Tecnologia Rural e Animal - Universidade Estadual do Sudoeste da Bahia.
}

\begin{abstract}
RESUMO - O objetivo com este trabalho foi avaliar a massa de matéria seca forragem e de seus componentes morfológicos, a altura e o índice de tombamento do pasto, a densidade volumétrica e o valor nutritivo da forragem em pastos de Brachiaria decumbens diferidos por 95 dias sob quatro estratégias de adubação nitrogenada. Foram estudadas quatro estratégias de aplicação de nitrogênio no início e no final do período chuvoso, respectivamente (0-0, 100-0, 50-50, 0-100 kg de N.ha $\left.{ }^{-1}\right)$, avaliados em três estratos verticais a cada $20 \mathrm{~cm}$, num delineamento experimental de blocos casualizados em esquema de parcelas subdivididas com quatro repetições. Os pastos adubados com $100 \mathrm{~kg}$ de $\mathrm{N}$ no final do período chuvoso apresentaram maiores massas de matéria seca de forragem total, lâmina de folha e de colmo verde, bem como altura, altura estendida e densidade volumétrica da forragem total, lâmina de folha e de colmo verde em todos os estratos estudados. Os índices de tombamento foram maiores para os pastos adubados no final do período chuvoso (0-100 e 50-50). Os percentuais de fibra em detergente neutro foram menores no estrato A (acima de $40 \mathrm{~cm}$ do solo) e os teores proteína bruta (PB) maiores em todos os estratos para os tratamentos 0-100 e 50-50. Embora a adubação com $100 \mathrm{~kg}$ de $\mathrm{N}$ no final do período chuvoso permita aumentar a massa de forragem total e de lâminas de folhas e melhorar a qualidade desta forragem, a maior densidade de colmos nos estratos superiores e o elevado índice de tombamento podem caracterizar dificuldades na seleção da forragem e redução no consumo e desempenho animal.
\end{abstract}

Palavras-chave: acamamento, adubação, densidade de forragem, estrato vertical, massa de forragem, pasto diferido

\section{Deferring of Brachiaria decumbens pastures fertilized with nitrogen at the beginning and the end of the rainy season}

\begin{abstract}
The objective of this research was to evaluate the forage dry matter yield and its morphological components, height and pasture falling index, bulk density and forage nutritional value in Brachiaria decumbens pastures deferred for 95 days under four strategies of nitrogen fertilization. It was studied four strategies of nitrogen application at the beginning and at the end of the rainy season, respectively $(0-0,100-0,50-50,0-100 \mathrm{~kg} N / h a)$ evaluated in three vertical strata at every $20 \mathrm{~cm}$ in a randomized block design in a split-plot arrangement with four replicates. Pastures fertilized with $100 \mathrm{~kg} \mathrm{~N}$ at the end of the rainy season showed greater weights of total forage dry matter, leaf blade and green stem as well as height, extended height and total forage bulk density, leaf blade and green stem in all strata studied. Falling indexes were greater for pastures fertilized at the end of the rainy season (0-100 and 50-50). The percentage of neutral detergent fiber were lower in stratum A (40 cm above ground), and contents of crude protein (CP) were greater in all strata for the treatments 0-100 and 50-50 Although fertilization with $100 \mathrm{~kg} \mathrm{~N}$ at the end of the rainy season allows an increase in the mass of total forage and leaf blades and improvement in the quality of this forage, greater density of stems in the upper strata and the high falling index can characterize difficulties in forage selection and reduction in intake and animal performance.
\end{abstract}

Key Words: deferred pasture, falling, fertilization, forage density, herbage mass, vertical stratum

\section{Introdução}

Dentre as estratégias utilizadas para equilibrar a demanda de forragem durante o período de escassez de forragem, destaca-se o diferimento de pastagens, pela praticidade e menor custo. Entretanto, esta estratégia pode não atingir metas de produtividade, pois, após o perfilhamento inicial, o contínuo aumento do rendimento forrageiro, em virtude principalmente do alongamento das hastes, resulta em crescente aumento da proporção de colmos, normalmente, pouco consumidos (Santos et al., 2004). 
A disponibilidade de matéria seca de forragem e as características morfológicas e estruturais das plantas variam durante o período de pastejo em virtude de sua evolução fenológica e do impacto do próprio pastejo (Carvalho et al., 2006), assim essas mudanças na estrutura do pasto diferido podem afetar o comportamento ingestivo dos animais. No ambiente de pastagens as características estruturais determinam o grau de pastejo seletivo exercido pelos animais, assim como a eficiência com a qual a forragem é colhida, por sua vez, afetando o consumo. Neste sentido, a compreensão da distribuição espacial dos principais componentes da forragem que afetam o consumo e o seu detalhamento nos diferentes estratos verticais pode evidenciar mais detalhadamente a dificuldade de seleção dos animais em pastejo.

Portanto, a disponibilidade de forragem e a estrutura da pastagem diferida podem ser potencializadas pelo manejo adequado da pastagem antes de seu diferimento, para evitar limitação ao consumo animal. A escolha da forrageira adequada, a duração do período de diferimento, a adubação nitrogenada, a época adequada para vedação e adubação dos pastos são ações de manejo fundamentais para garantir que as metas de produção de forragem, em quantidade e qualidade, sejam atingidas. Adubação no início do verão poderia proporcionar pouco acúmulo de forragem no momento do diferimento, em contrapartida, Martha Jr. et al. (2004) relataram que a fertilização nitrogenada, quando realizada tardiamente no verão ou outono (início do diferimento), quando a umidade do solo começa a reduzir, pode resultar em perdas de nitrogênio por volatilização.

O objetivo com a condução deste trabalho foi de avaliar a produção, o valor nutritivo da forragem e algumas características estruturais do pasto de Brachiaria decumbens diferido durante o período de 95 dias sob quatro estratégias de adubação nitrogenada.

\section{Material e Métodos}

O experimento foi conduzido no Setor de Bovinocultura da Universidade Estadual do Sudoeste da Bahia - UESB,
Campus de Itapetinga, BA, região Sudoeste da Bahia, localizada a $15^{\circ} 18^{\prime} 14^{\prime \prime}$ de latitude sul e $40^{\circ} 12^{\prime} 10^{\prime \prime}$ de longitude oeste e altitude de $268 \mathrm{~m}$, durante o período de novembro de 2008 a novembro de 2009. O clima da região é do tipo “Cw” mesotérmico úmido e subúmido, quente e com inverno seco, pela classificação de Köppen. O período de verão é quente e chuvoso e abrange os meses de outubro a março, enquanto o período frio é seco, sem chuvas, e inclui os meses de abril a setembro. A precipitação média anual é de $852 \mathrm{~mm}$, e o período considerado de seca vai de maio a outubro ( $25 \%$ da precipitação anual) e temperatura média anual de $27^{\circ} \mathrm{C}$ (Tabela 1). O solo da área experimental é um Chernossolo Argilúvio hipereutrófico, de textura francoarenosa e com relevo levemente ondulado.

O delineamento experimental adotado foi o de blocos casualizados em esquema de parcelas subdivididas com quatro repetições. Os tratamentos foram distribuídos aleatoriamente em quatro blocos (piquetes) de $441 \mathrm{~m}^{2}$, cercados com fios de arame liso eletrificado, divididos em quatro parcelas de $100 \mathrm{~m}^{2}(10 \times 10 \mathrm{~m})$, descontando-se a bordadura. O experimento foi instalado em uma pastagem formada em 1993 com sementes de Brachiaria decumbens, cujo preparo do solo para implantação consistiu nas práticas de aração, gradagem e adubação de estabelecimento. De uma maneira geral o pasto era uniforme e apresentava um bom estande de plantas. No dia 27 de novembro de 2008 foi realizado um pastejo de uniformização, logo em seguida a marcação da área das parcelas e por fim a coleta de amostras de solos, à profundidade de 0 a $20 \mathrm{~cm}$, cujos resultados das análises química foram: $\mathrm{pH}$ em água = 5,6; P disponível = $2,5 \mathrm{mg} / \mathrm{dm}^{3} ; \mathrm{K}=0,3 \mathrm{Cmol}_{\mathrm{c}} / \mathrm{dm}^{3} ; \mathrm{Ca}=2,4 \mathrm{eMg}=1,9 \mathrm{Cmol}_{\mathrm{C}} / \mathrm{dm}^{3}$; $\mathrm{Al}=0,1$ e $\mathrm{H}+=2,6 \mathrm{Cmol}_{\mathrm{c}} / \mathrm{dm}^{3}$, não houve necessidade de calagem nos pastos.

Foram estudadas as combinações entre estratégias de aplicação do nitrogênio, casualizadas as parcelas, e as alturas de colheita de forragem nos estratos verticais, casualizadas as subparcelas. Foram estudadas as estratégias de aplicação de nitrogênio no início e no final do período chuvoso, respectivamente(0-0, 100-0, 50-50, 0-100 kg de N/ha),

Tabela 1 - Médias mensais da temperatura média diária, temperatura máxima, temperatura mínima e precipitação pluvial total mensal e evaporação total mensal durante os períodos de novembro de 2008 a julho de 2009

\begin{tabular}{lcccc}
\hline Mês/Ano & Temperatura média $\left({ }^{\circ} \mathrm{C}\right)$ & Temperatura máxima $\left({ }^{\circ} \mathrm{C}\right)$ & Temperatura mínima $\left({ }^{\circ} \mathrm{C}\right)$ & Precipitação $(\mathrm{mm})$ \\
\hline Novembro/2008 & 26,4 & 35,0 & 21,0 & 1,0 \\
Dezembro/2008 & 26,8 & 35,0 & 21,0 & 13,4 \\
Janeiro/2009 & 27,6 & 35 & 20,0 & 78,3 \\
Fevereiro/2009 & 28,0 & 34,0 & 20,0 & 5,6 \\
Março/2009 & 28,9 & 37,0 & 21,0 & 17,0 \\
Abril/2009 & 27,6 & 36,0 & 16,0 & 17,4 \\
Maio/2009 & 25,2 & 36,0 & 15,0 & 41,1 \\
Junho/2009 & 23,9 & 35,0 & 3,0 & 6,1 \\
Julho/2009 & 26,0 & 35,0 & &
\end{tabular}


avaliadas em três estratos verticais denominados: estrato A, acima de $40 \mathrm{~cm}$; B, 20-40 cm; e C, 0-20 cm do solo. A adubação nitrogenada na forma de uréia foi aplicada no final de novembro de 2008, para o tratamento 100-0 e a primeira dose do tratamento 50-50, caracterizando o início do período chuvoso e em meados de março de 2009 foram adubados os tratamentos 0-100 e a segunda dose do tratamento 50-50. Durante o período de novembro de 2008 a março de 2009, os piquetes (blocos) foram manejados sob lotação intermitente com período de descanso de 28 dias, utilizando novilhas Holandês/Zebu com peso corporal médio de 150 kg, como animais reguladores, colocados e removidos do piquete de acordo com a disponibilidade de forragem, assegurando, entre os tratamentos, uma altura no póspastejo em torno de $15 \mathrm{~cm}$.

Antes da vedação, os pastos foram utilizados intensivamente, rebaixados para $10 \mathrm{~cm}$ de altura e após a última parcela da adubação nitrogenada, 21 de março, os pastos foram vedados a entrada dos animais até o dia 24 de junho de 2009, perfazendo um período de 95 dias. Após o período de vedação, antes da entrada dos animais, foram medidas as alturas do pasto e da planta estendida em dez pontos de cada parcela, utilizando-se o instrumento descrito por Fagundes et al. (2006), tomando como critério a distância entre a parte da planta localizada mais alto no dossel e o nível do solo. A altura da planta estendida foi mensurada estendendo-se os perfilhos da gramínea no sentido vertical e anotando-se a maior distância do nível do solo até o ápice dos perfilhos, determinando assim, o índice de tombamento das plantas descrito por Santos et al. (2009a), que teve como finalidade determinar, de forma menos subjetiva, o grau de acamamento constatado em alguns pastos diferidos e foi calculado pelo quociente entre a altura da planta estendida e a altura do pasto.

Para determinação da massa de forragem e de seus componentes morfológicos, e em função da grande quantidade de forragem acumulada e das características estruturais das plantas, as amostras foram colhidas de forma estratificada de $20 \mathrm{em} 20 \mathrm{~cm}$ partindo-se do topo do dossel, em três estratos verticais A, B e C, com auxílio de um equipamento denominado estratificador, construído com ferro de construção de $1 / 4$ de polegada, com dimensões de $70 \mathrm{~cm} \times 70 \mathrm{~cm}\left(0,49 \mathrm{~m}^{2}\right)$ e $140 \mathrm{~cm}$ de altura. Para guiar a altura do corte, um quadrado de ferro era acoplado ao estratificador, sendo sustentado por ganchos de metal (Hack et al., 2007). A densidade volumétrica da forragem e de seus componentes morfológicos, expressa em $\mathrm{kg} / \mathrm{cm} / \mathrm{ha}$, foi calculada pela divisão da massa de forragem e da massa de seus componentes morfológicos, respectivamente, pela altura do pasto.
As amostras colhidas foram acondicionadas em sacos plásticos e foram pesadas, em seguida homogeneizadas e divididas em duas amostras representativas: uma foi separada em lâmina foliar, colmo (bainha e colmo) e forragem morta, considerando a proporção de cada componente morfológico e após a separação, os componentes foram acondicionados em saco de papel, pesados e secos em estufa de circulação forçada de ar a $60^{\circ} \mathrm{C}$, por 72 horas. A outra amostra também foi acondicionada em saco de papel, pesada e seca em estufa de circulação forçada de ar regulada a $60{ }^{\circ} \mathrm{C}$, durante 72 horas. Nas amostras de forragem total, depois de trituradas em moinho tipo Willey com peneira de $1 \mathrm{~mm}$, determinaram-se os teores de matéria seca (MS), nitrogênio total, fibra em detergente neutro (FDN) conforme procedimentos descritos por Silva \& Queiroz (2002). A FDN indigestível (FDNi) foi estimada considerando a digestibilidade in situ, por 240 horas no rúmen de novilhos fistulados mestiços Holandês/Zebu e a matéria seca potencialmente digestível (MSpoD) foi calculada de acordo com Paulino et al. (2006).

Os dados foram analisados por meio de análise de variância por um modelo matemático com os efeitos fixos de tratamento, estrato e bloco e a interação entre esses fatores. A interação foi desdobrada, ou não, de acordo com a sua significância. Os efeitos das parcelas e subparcelas foram avaliados pela aplicação do teste Tukey a 5\% de probabilidade, por se tratar de dados qualitativos, também foram observados os coeficientes de determinação. No caso das características altura, altura estendida e índice de tombamento foram realizadas as análises de variância por um modelo matemático com os efeitos fixos de tratamento e bloco, aplicando o teste Tukey a 5\% de probabilidade, além dos coeficientes de determinação. Para realizar as análises estatísticas foi utilizado o Sistema de Análises Estatísticas e Genéticas - SAEG (Ribeiro Junior, 2001).

\section{Resultados e Discussão}

Verificou-se que a maior $(\mathrm{P}<0,05)$ massa de forragem acumulada, $7.997 \mathrm{~kg}$ de $\mathrm{MS}_{\text {.ha }}{ }^{-1}$, foi encontrada nos pastos diferidos por 95 dias quando receberam aplicação de $100 \mathrm{~kg}$ de N.ha-1 realizada no final do período chuvoso (0-100). Essa estratégia de adubação proporcionou um aumento de 15,4\% em relação à adubação parcelada 50 kg de $\mathrm{N}$ no início e $50 \mathrm{~kg}$ de $\mathrm{N}$ no final das águas (50-50), que promoveu produção de 6.763 kg e de 22,1\% em relação ao tratamento controle (0-0), de $6.227 \mathrm{~kg}$ de $\mathrm{MS} \mathrm{ha}^{-1}$. A maior produção de forragem associada a aplicação de maior quantidade de $\mathrm{N}$ num período mais próximo a vedação do pasto pode ser explicada, considerando que o $\mathrm{N}$ é um dos 
nutrientes com maior dinâmica no sistema, prontamente disponíveis, principalmente, na forma nítrica e amoniacal, resultante da aplicação direta do fertilizante nitrogenado (Primavesi et al., 2006). Por outro lado, a retirada do N com o pastejo realizado entre o início do período chuvoso, após a aplicação do adubo e o diferimento, nos tratamentos 100-0 e 50-50, adicionalmente as perdas de $\mathrm{N}$ no solo após aplicação, podem ter resultado também na saída de $\mathrm{N}$ do sistema. Parte do $\mathrm{N}$ aplicado à pastagem é freqüentemente perdido do sistema, o que reduz a eficiência de seu uso (Martha Júnior et al., 2004) e uma das principais vias de perda é a volatilização de amônia $\left(\mathrm{NH}_{3}\right)$, principalmente quando a uréia é aplicada a lanço e em cobertura no final do período das chuvas (Primavesi et al., 2001). Esses valores podem ser considerados próximos aos 7.665 kg de MS.ha-1 relatados por Santos et al. (2009a) em pastos de Brachiaria diferido por maiores períodos, 116 dias.

Foi verificado interação $(\mathrm{P}<0,05)$ entre as estratégias de adubação (parcelas) e a altura de corte nos estratos (subparcelas) em todas as características estudadas nestas condições. Com o desdobramento da interação verificou que a massa de forragem total também foi superior $(\mathrm{P}<0,05)$ para o tratamento 0-100 em todos os estratos verticais avaliados (Tabela 2). Segundo Primavesi et al. (2004), com a aceleração da taxa de crescimento das plantas, o nitrogênio eleva a produção de matéria seca dentro dos estratos verticais da pastagem, aumentando o rendimento forrageiro e consequentemente a capacidade de suporte. Certamente a maior disponibilidade de N próximo ao período de vedação da pastagem contribuiu para maior taxa de perfilhamento, além de favorecer a maior capacidade de formação de gemas axilares que, potencialmente, deram origem a novos perfilhos (Silva et al., 2008). Destaca-se que a massa de forragem produzida no estrato A para o tratamento 0-100 contribuiu para o acréscimo de 70,5\% da forragem produzida em relação ao tratamento controle.

Embora o sucesso do pastejo diferido é dependente da massa de forragem residual por ocasião da vedação, o consumo e desempenho animal parece estar mais relacionado a disponibilidade de matéria seca verde (Silva et al., 2009), soma da massa de lâmina foliar (LF) e massa de colmo verde,

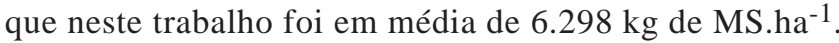
Dentre estes componentes, as folhas assumem papel importante, pois são primeiramente selecionadas pelos animais especialmente nos estratos superiores do dossel. Neste estudo as maiores produções de LF nos estratos A e B foram encontradas no tratamento 0-100, respectivamente (Tabela 2). Esses resultados comprovam que a maior aplicação de nitrogênio 0-100 próximo ao período de vedação do pasto favoreceu a maior produção de lâminas de folhas, confirmando o rápido efeito do nitrogênio em aumentar a taxa de fotossíntese das plantas e o maior fornecimento de fotoassimilados para os tecidos de crescimento. Segundo Silva et al. (2008) a adubação nitrogenada afeta o alongamento foliar e a taxa de perfilhamento, apresentando leve efeito sobre a taxa de aparecimento de folhas, o tamanho

Tabela 2 - Massas de forragem total e dos seus componentes morfológicos em pastos de Brachiaria decumbens diferidos sob quatro estratégias de adubação nitrogenada e colhidos em três estratos verticais

\begin{tabular}{|c|c|c|c|c|c|}
\hline \multirow[t]{2}{*}{ Estrato } & \multicolumn{4}{|c|}{ Adubação $^{1}$} & \multirow[t]{2}{*}{ Coeficiente de variaçãc } \\
\hline & $0-0$ & $0-100$ & $50-50$ & $100-0$ & \\
\hline \multicolumn{6}{|c|}{ Massa de forragem total $\left(\mathrm{kg}\right.$ de MS.ha $\left.^{-1}\right)$} \\
\hline A & 363Cd & $1.230 \mathrm{Ca}$ & 527Cc & $653 \mathrm{Cb}$ & \multirow{3}{*}{2,1} \\
\hline $\mathrm{B}$ & $1.420 \mathrm{Bd}$ & $2.336 \mathrm{Ba}$ & $2.096 \mathrm{Bb}$ & $1.729 \mathrm{Bc}$ & \\
\hline $\mathrm{C}$ & $4.444 \mathrm{Aa}$ & $4.432 \mathrm{Aa}$ & $4.141 \mathrm{Ab}$ & $3.892 \mathrm{Ac}$ & \\
\hline \multicolumn{5}{|c|}{ Massa de forragem total (kg de MS.ha $^{-1}$ ) } & \multirow[b]{2}{*}{2,2} \\
\hline Total & $6.228 c$ & 7.997a & $6.764 b$ & $6.273 c$ & \\
\hline \multicolumn{5}{|c|}{ 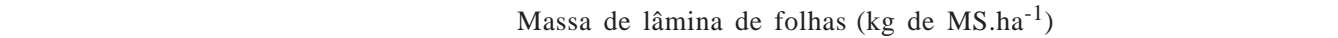 } & \multirow{4}{*}{4,9} \\
\hline A & 308Cd & $1.084 \mathrm{Ba}$ & 463Bс & $562 \mathrm{Cb}$ & \\
\hline B & 579Bd & 1.319Aa & $1.141 \mathrm{Ab}$ & 753Bc & \\
\hline \multirow[t]{2}{*}{$\mathrm{C}$} & $586 \mathrm{Ac}$ & $1.024 \mathrm{Bb}$ & $1.171 \mathrm{Aa}$ & $1.197 \mathrm{Aa}$ & \\
\hline & \multicolumn{4}{|c|}{ Massa de colmo verde (kg de MS.ha $^{-1}$ ) } & \multirow{4}{*}{3,3} \\
\hline A & $56 \mathrm{Cb}$ & 146Cab & 60Cb & 91Cab & \\
\hline $\mathrm{B}$ & $817 \mathrm{Bb}$ & $958 \mathrm{Ba}$ & $903 \mathrm{Ba}$ & $931 \mathrm{Ba}$ & \\
\hline \multirow[t]{2}{*}{$\mathrm{C}$} & 3.165Aab & $3.122 \mathrm{Aa}$ & $2.655 \mathrm{Ab}$ & $2.105 \mathrm{Acb}$ & \\
\hline & \multicolumn{4}{|c|}{ Massa de forragem morta (kg de $\left.\mathrm{MS} . \mathrm{ha}^{-1}\right)$} & \multirow{4}{*}{11,2} \\
\hline A & 0C & 0C & $0 \mathrm{C}$ & $0 \mathrm{C}$ & \\
\hline B & $25 \mathrm{Ba}$ & $53 \mathrm{Ba}$ & $52 \mathrm{Ba}$ & $45 \mathrm{Ba}$ & \\
\hline $\mathrm{C}$ & $695 \mathrm{Aa}$ & $311 \mathrm{Ac}$ & 329Ac & $590 \mathrm{Ab}$ & \\
\hline
\end{tabular}

Médias seguidas de letras minúsculas distintas na linha e de letras maiúsculas distintas na coluna diferem $(\mathrm{P}<0,05)$ pelo teste Tukey.

${ }^{1} \mathrm{~kg}$ de N.ha-1 ${ }^{-1}$, aplicado no final de novembro e meados de março. 
final da folha é aumentado, além de favorecer a maior capacidade de formação de gemas axilares que, potencialmente, poderão dar origem a novos perfilhos. Além disso, as chuvas e somadas as altas temperaturas no final de março podem ter favorecido a eficiência de utilização do $\mathrm{N}$ pelas plantas, enquanto que as baixas temperaturas durante o diferimento (Tabela 1), período de desenvolvimento dos perfilhos, podem ter resultado em maior duração de vida das folhas.

Apesar da maior massa de forragem total e de lâmina de folhas tenham sido fatores positivos com a maior aplicação de $\mathrm{N}$ próximo ao período de vedação, foram encontrados neste tratamento (0-100) valores elevados de massa de colmo em todos os estratos, destacando que o estrato A cuja massa de colmos foi aproximadamente três vezes maior que os outros tratamentos (Tabela 2), o que caracterizaria uma barreira estrutural para o consumo dos animais. Esses valores podem ser explicados pelo aumento no número de perfilhos por unidade de área, e principalmente pelo aumento do peso dos perfilhos, pois estes colmos mais desenvolvidos garantem a sustentação das folhas, as quais foram progressivamente sombreadas pelo desenvolvimento do índice de área foliar (Lemaire et al., 1991), pode ter promovido uma remobilização e direcionamento do $\mathrm{N}$ dessas folhas para os colmos ou tecidos de suporte, especialmente para o crescimento de novas folhas no topo do dossel, em estratos mais iluminados.

O diferimento leva ao acúmulo de colmo maduro e material morto e decréscimo na disponibilidade de folhas, com consequente diminuição do consumo e desempenho animal. Por essas razões, Santos et al. (2004) concluíram que nem sempre é verdadeira a premissa de que o aumento da disponibilidade de forragem, por meio do diferimento, embora aumente a oportunidade de seleção de pasto. A quantidade de forragem morta é um dos principais fatores que podem dificultar a seleção de forragem verde pelos animais. No presente estudo, não houve presença de forragem morta no estrato A, enquanto no estrato B não foi constatada diferença entre os tratamentos No entanto, as menores massas de forragem morta foram encontradas nos tratamentos adubados com nitrogênio no final do período chuvoso (0-100 e 50-50) no estrato C, mais próximo ao solo, o que poderia favorecer o consumo animal (Tabela 2). O déficit hídrico durante o período de diferimento aumenta a senescência das folhas, segundo Wolfe et al. (1988) o solo seco não pode fornecer nitrogênio suficiente para suprir as necessidades de crescimento da cultura e o nitrogênio do interior da planta é redistribuído das folhas mais velhas para os pontos de crescimento. Entretanto, a intensidade da senescência depende da quantidade de nitrogênio no solo, das reservas de nitrogênio na planta e da demanda de nitrogênio dos pontos de crescimento, o que pode ter beneficiado aquelas plantas que foram adubadas próximo ao período de diferimento.

A altura da planta estendida foi maior $(\mathrm{P}<0,05)$ para $\mathrm{o}$ tratamento adubado com $100 \mathrm{~kg}$ de $\mathrm{N}$ no final do período chuvoso (0-100) seguido do tratamento parcelado (50-50) (Tabela 3). Esses resultados podem ser atribuídos à intensificação da competição promovida pela adubação nitrogenada próximo ao período de diferimento, como uma das respostas à competição por luz, que segundo Santos et al. (2009a), a elevação da taxa de alongamento do colmo, os perfilhos tornam-se maiores (maior peso e comprimento) e os pastos e as plantas apresentam maior altura. De acordo com os autores, em pastagens diferidas, é comum constatar a formação de uma estrutura de pasto peculiar, caracterizada pelo posicionamento dos perfilhos no sentido horizontal, e uma das consequências dessa estrutura é o possível aumento das perdas de forragem durante o pastejo, bem como a menor eficiência de utilização da forragem produzida com o acamamento das plantas.

Utilizando-se a metodologia proposta por Santos et al. (2009b) para mensurar o índice de tombamento em pastos diferidos, foram encontrados os índices de tombamento (IT) mais elevados $(\mathrm{P}<0,05)$ para os tratamentos que receberam adubação nitrogenada no final do período chuvoso (0-100 e 50-50) (Tabela 3). A adubação nitrogenada próximo ao período de vedação favoreceu o alongamento dos colmos do capim Brachiaria decumbens o qual apresenta colmo delgado e flexível próprio desta cultivar, o

Tabela 3 - Altura do pasto, da planta estendida e índice de tombamento pastos de Brachiaria decumbens diferidos, sob quatro estratégias de adubação nitrogenada e colhidos em três estratos verticais

\begin{tabular}{|c|c|c|c|c|c|c|}
\hline \multirow[t]{2}{*}{ Variável } & \multicolumn{4}{|c|}{ Adubação } & \multirow[t]{2}{*}{ Média } & \multirow[t]{2}{*}{ CV } \\
\hline & $0-0$ & $0-100$ & $50-50$ & $100-0$ & & \\
\hline Altura do pasto $(\mathrm{cm})$ & $69,1 \mathrm{ab}$ & $73,2 \mathrm{a}$ & $66,2 b$ & 73,3a & 70,4 & 3,2 \\
\hline Altura da planta estendida $(\mathrm{cm})$ & $93,8 \mathrm{c}$ & $127,8 \mathrm{a}$ & $115,3 b$ & $102,7 \mathrm{c}$ & 109,9 & 4,2 \\
\hline Índice de tombamento ${ }^{1}$ & $1,4 \mathrm{~b}$ & $1,7 \mathrm{a}$ & $1,7 \mathrm{a}$ & $1,4 \mathrm{~b}$ & 1,6 & 3,5 \\
\hline
\end{tabular}


que torna as plantas sujeitas ao tombamento. Segundo Santos et al. (2009a), a ocorrência de tombamento dos perfilhos em pastos diferidos pode ser reduzida com a adoção de menores períodos de diferimento ou com a aplicação de menor dose de nitrogênio na data de diferimento da pastagem. Portanto, a adubação nitrogenada em pastagens diferidas deve ser efetuada com critério, considerando-se todos os efeitos no acúmulo de forragem, ou seja, doses muito elevadas de $\mathrm{N}$ podem resultar na perda da qualidade da forragem acumulada, possivelmente com o alongamento dos colmos. Os índices de tombamento do presente trabalho cujo período de diferimento teve duração de 95 dias, foi de 1,7 para os tratamentos 0-100 e 50-50 e de 1,4 para os tratamentos 0-0 e 100-0, respectivamente, e foram superiores à 1,16 estimado para o mesmo período de diferimento pela equação $\hat{Y}=0,4796+0,007132 * D$, proposta por Santos et al. (2009a).

A densidade volumétrica parece ser a principal característica do dossel a determinar a taxa de consumo e não a altura isoladamente, em forrageiras tropicais, especialmente quando a proporção de hastes e o material morto na massa da forragem do dossel são relativamente altos, como é o caso de pastagens diferidas. No presente trabalho a densidade de forragem total e de lâmina foliar foi maior $(\mathrm{P}<0,05)$ para o tratamento $0-100$ seguido do $50-50$ nos estratos A e B (Tabela 4). O acamamento observado nestes tratamentos provavelmente resultou no aumento da densidade volumétrica da forragem nos estratos, considerando que a mesma quantidade de massa de forragem por unidade de área passa a ocupar menor altura do pasto. Essa alteração na densidade volumétrica da forragem, em conjunto com a sua composição morfológica, determinam mudanças estruturais no pasto que interferem no comportamento ingestivo animal (Gomide \& Gomide, 2001). Assim, a determinação da massa de forragem total é insuficiente para caracterizar, de forma mais completa, a forragem da pastagem diferida, já que esta pode ter composição morfológica, densidade volumétrica e valor nutritivo bastante distinto nos diferentes estratos estudados. Não houve diferença $(\mathrm{P}<0,05)$ na densidade de colmo nos estratos A e B, constatando maiores valores no estrato C para os tratamentos controle $0-0$ e $0-100$. A densidade de forragem morta foi menor $(\mathrm{P}<0,05)$ nos tratamentos que receberam adubação nitrogenada no final do período chuvoso, 0-100 e 50-50 (Tabela 4).

O valor médio da densidade volumétrica de lâminas foliares, $38,1 \mathrm{~kg} . \mathrm{cm} \cdot \mathrm{ha}^{-1}$, pode ser considerado alto quando comparado aos $25,48 \mathrm{~kg} / \mathrm{cm} / \mathrm{ha}$ encontrado por Santos et al. (2009a), e os baixos valores de forragem morta especialmente para os tratamentos adubados próximo a vedação (0-100 e 50-50), podem ser considerados resultados positivos para o consumo animal. Por outro lado, as elevadas densidades de colmo verde encontradas nestes tratamentos (Tabela 4) poderiam constituir barreira à desfolhação, reduzindo a facilidade de colheita da forragem pelo animal em pastejo (Carvalho et al., 2005), uma vez que o consumo máximo ocorre quando os animais estão em pastagens com alta densidade de folhas acessíveis (Euclides et al.,1999). Maiores densidades de colmos no pasto diferido já eram esperadas, pois esta é uma característica particular deste tipo de manejo, entretanto, os animais em pastejo também consumem os colmos verdes em pastos diferidos, à medida que a seleção por folhas vai sendo dificultada.

Tabela 4 - Densidade volumétrica de lâmina de folha, colmo verde, forragem morta e forragem total em pastos de Brachiaria decumbens diferidos, sob quatro estratégias de adubação nitrogenada e colhidos em três estratos verticais

\begin{tabular}{|c|c|c|c|c|c|}
\hline \multirow[t]{2}{*}{ Estrato } & \multicolumn{4}{|c|}{ Adubação $^{1}$} & \multirow[t]{2}{*}{ Coeficiente de variação } \\
\hline & $0-0$ & $0-100$ & $50-50$ & $100-0$ & \\
\hline \multicolumn{5}{|c|}{ Densidade de forragem total (kg de MS.cm.ha-1) } & \multirow{4}{*}{2,2} \\
\hline A & 13,6 Сс & $29,5 \mathrm{Ca}$ & $15,6 \mathrm{Cbc}$ & $19,8 \mathrm{Cbc}$ & \\
\hline $\mathrm{B}$ & $71,0 \mathrm{Bdc}$ & $116,8 \mathrm{Ba}$ & $104,8 \mathrm{Bb}$ & $86,4 \mathrm{Bc}$ & \\
\hline \multirow[t]{2}{*}{$\mathrm{C}$} & $222,2 \mathrm{Aac}$ & $221,6 \mathrm{Aa}$ & $207,1 \mathrm{Ab}$ & 194,6 Ac & \\
\hline & \multicolumn{4}{|c|}{ Densidade de lâmina de folhas (kg de MS.cm.ha ${ }^{-1}$ ) } & \\
\hline A & 11,6 Сс & $26,0 \mathrm{Ca}$ & $13,7 \mathrm{Bbc}$ & $17,1 \mathrm{Cbc}$ & \\
\hline $\mathrm{B}$ & $28,9 \mathrm{Bdc}$ & $65,9 \mathrm{Aa}$ & $57,1 \mathrm{Ab}$ & $37,6 \mathrm{Bc}$ & 5,8 \\
\hline \multirow[t]{2}{*}{$\mathrm{C}$} & $29,3 \mathrm{Ac}$ & $51,2 \mathrm{Bb}$ & $58,5 \mathrm{Aa}$ & $59,8 \mathrm{Aa}$ & \\
\hline & \multicolumn{4}{|c|}{ Densidade de colmo verde (kg de MS.cm.ha ${ }^{-1}$ ) } & \\
\hline A & 2,1Ca & $3,5 \mathrm{Ca}$ & $1,8 \mathrm{Ca}$ & $2,8 \mathrm{Ca}$ & \\
\hline $\mathrm{B}$ & $40,9 \mathrm{Bb}$ & $47,9 \mathrm{Ba}$ & $45,2 \mathrm{Ba}$ & $46,6 \mathrm{Ba}$ & 3,2 \\
\hline \multirow[t]{2}{*}{$\mathrm{C}$} & $158,2 \mathrm{Aa}$ & $156,1 \mathrm{Aa}$ & $132,7 \mathrm{Ab}$ & $105,3 \mathrm{Ac}$ & \\
\hline & \multicolumn{4}{|c|}{ Densidade de forragem morta (kg de MS.cm.ha ${ }^{-1}$ ) } & \\
\hline A & $0,0 \mathrm{C}$ & $0,0 \mathrm{C}$ & $0,0 \mathrm{C}$ & $0,0 \mathrm{C}$ & \\
\hline $\mathrm{B}$ & $1,2 \mathrm{Ba}$ & $3,0 \mathrm{Ba}$ & $2,6 \mathrm{Ba}$ & $2,3 \mathrm{Ba}$ & 11,1 \\
\hline $\mathrm{C}$ & $34,7 \mathrm{Aa}$ & $15,5 \mathrm{Ac}$ & $16,3 \mathrm{Ac}$ & $29,5 \mathrm{Ab}$ & \\
\hline
\end{tabular}

Médias seguidas de letras minúsculas distintas na linha e de letras maiúsculas distintas na coluna diferem $(\mathrm{P}<0,05)$ pelo teste tukey.

${ }^{1} \mathrm{~kg}$ de N.ha-1 ${ }^{-1}$ aplicado no final de novembro e meados de março. 
O uso de adubos nitrogenados exercem efeitos positivos na produção e no valor nutricional da forragem (Andrade et al., 2003), com o aumentando a densidade da forragem e, sobretudo, a disponibilidade de folhas. Maiores $(\mathrm{P}<0,05)$ teores de $\mathrm{PB}$ foram verificados para os tratamentos que receberam adubação nitrogenada no final do período chuvoso, em todos os estratos estudados, devendo-se destacar que não houve diferença $(\mathrm{P}<0,05)$ entre os tratamentos 0-100 e 50-50 (Tabela 5). Os teores 12,3 e $11,3 \%$ de PB verificados nos tratamentos 0-100 e 50-50 do estrato A, com média de $86,1 \%$ de folhas, são semelhantes aos 12,4\% encontrados por Magalhães et al. (2007) nas folhas de Brachiaria decumbens que receberam esta mesma dose de N. Vitor et al. (2009) verificaram aumento no teor de PB de lâminas foliares e pseudocolmo do capim elefante com o aumento das doses de N, explicando, após absorvido pelas plantas, na forma de nitrato, é reduzido à forma amoniacal, por meio das atividades das enzimas redutase do nitrato e redutase do nitrito e, por fim, assimilado aos esqueletos carbônicos via ciclo do ácido glutâmico e glutamina, que é precursor de vários aminoácidos. Os valores de $\mathrm{PB}$ encontrados nos estratos A e B de todos os tratamentos neste estudo (Tabela 5) podem ser considerados satisfatórios considerando o nível crítico de PB na dieta, abaixo do qual o consumo é reduzido pela deficiência de $\mathrm{N}$, estimado entre 6 e 7\% para as gramíneas tropicais (Minson, 1990). Dubeux Junior et al. (1997), em trabalho desenvolvido na região da Zona da Mata, verificaram valores de 7,9\% de PB na parte aérea, enquanto Paciullo et al. (2003) reportaram teores de 8,6\% de PB em pastagens de Brachiaria decumbens. Entretanto Euclides et al. (2007), considerando a dieta simulada pelo pastejo do animal, constataram que o conteúdo de PB esteve abaixo do valor crítico, estimado por Minson (1999) em pastos diferidos de Brachiaria cultivares Basilisk e Marandu.

Além dos fatores ligados ao comportamento ingestivo e estrutura do dossel, a FDN por estar diretamente associada ao efeito de enchimento do rúmen e inversamente proporcional a concentração energética da dieta, e pode ser usado para caracterizar o controle do consumo (Mertens, 1992), mecanismo válido quando a forragem já se encontra dentro do trato digestório do animal. Como já eram esperados os percentuais de FDN foram maiores $(\mathrm{P}<0,05)$ no estrato $\mathrm{C}$, em relação aos demais estratos, em todos os tratamentos estudados, o que pode ser atribuído a maior massa de colmos e forragem morta neste estrato. Os resultados de FDN encontrados neste estudo podem ser considerados próxmo à média de 74,5\% (mínimo de 64,5 e máximo de 86,7\%), das composições bromatológicas do Brachiaria decumbens no período seco sob pastejo, relatados por Silva et al. (2009), os quais fizeram uma compilação de vários trabalhos da literatura brasileira acerca do tema.

Contrariando os resultados médios de 76,2\% de FDN relatados por Moreira et al. (2009), que não encontraram diferenças $(\mathrm{P}>0,10)$ da aplicação de $\mathrm{N}$ sobre os teores de FDN. O valor médio de FDN encontrado no estrato $B$ foi de $73,4 \%$, destacando menores $(\mathrm{P}<0,05)$ valores no estrato A, 63,5 e 65,2\% para os tratamentos 0-100 e 50-50, respectivamente. Esses resultados estão de acordo com os relatados por Vitor et al. (2009), cujos teores FDN e da

Tabela 5 - Composição bromatológica de pastos de Brachiaria decumbens diferidos, sob quatro estratégias de adubação nitrogenada e colhidos em três estratos verticais

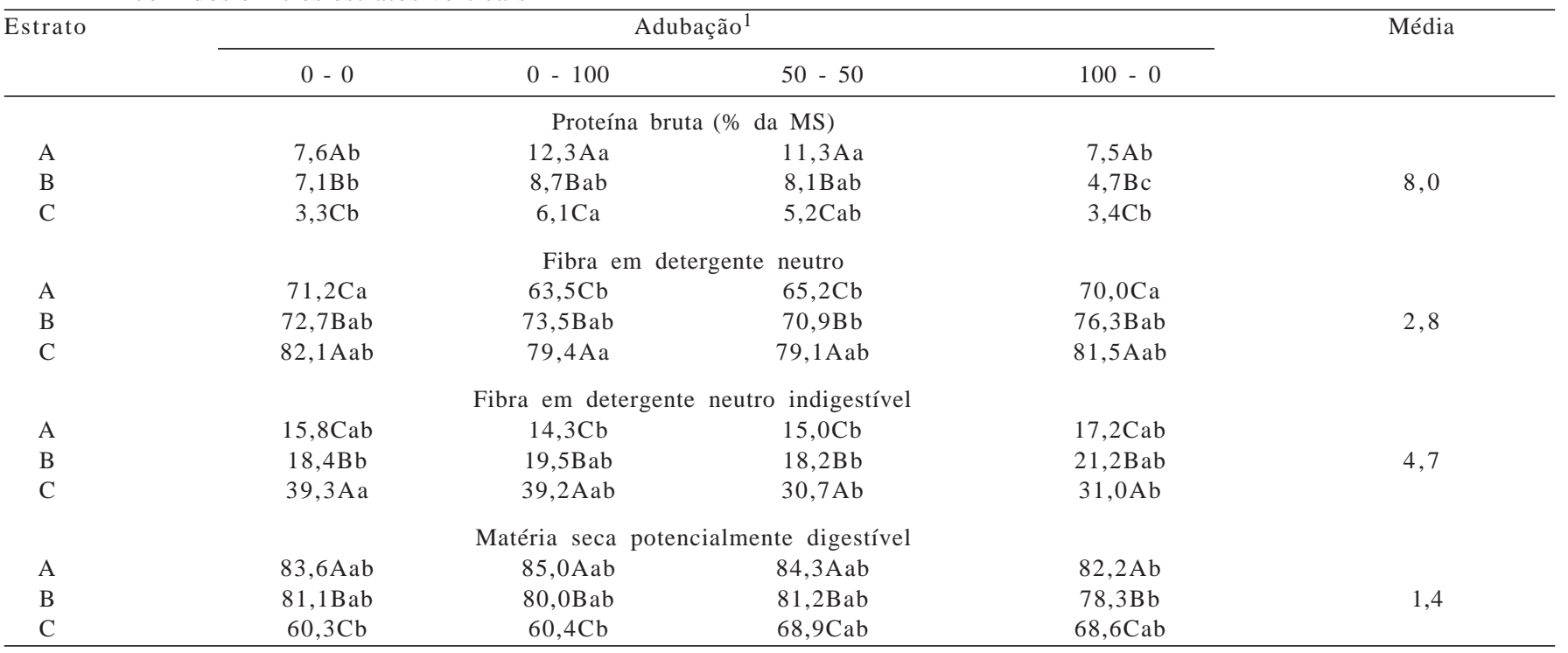

Médias seguidas de letras minúsculas distintas na linha e de letras maiúsculas distintas na coluna diferem $(\mathrm{P}<0,05)$ pelo teste tukey.

${ }^{1} \mathrm{~kg}$ de N.ha ${ }^{-1}$, aplicado no final de novembro e meados de março. 
digestibilidade da MS decresceram com as doses de N durante todo o ano, pois o $\mathrm{N}$ estimula o crescimento de tecidos novos, que possuem elevados teores de proteína, menores teores de carboidratos estruturais e lignina na matéria seca. Por outro lado, o fornecimento de $\mathrm{N}$ em doses elevadas, aliado a condições climáticas favoráveis, pode acelerar a maturidade e senescência da planta, limitando o efeito benéfico da adubação nitrogenada sobre os valores de FDN e reduzindo a digestibilidade da matéria seca, pois a porcentagem de parede celular na matéria seca é inversamente correlacionada ao teor de PB (Vitor et al., 2009).

Houve diferença $(\mathrm{P}<0,05)$ dos valores de FDN indigestível(FDNi)e de Matéria seca potencialmente digestível (MSpoD) entre os estratos estudados, constatando-se maiores valores de FDNi para o estrato $\mathrm{C}$, seguido do estrato B, com menores valores para o estrato A. Foi observado comportamento inverso para os parâmetros de MSpoD, não constatando diferença $(\mathrm{P}<0,05)$ para os tratamentos estudados (Tabela 5). Por outro lado, não foi verificado efeito $(\mathrm{P}<0,05)$ da aplicação de $\mathrm{N}$ sobre a FDNi, nos estratos estudados, com valores médios de 15,6, 19,3 e $35 \%$ para os estratos A, B e C, respectivamente. Os valores dos estratos A e B podem ser considerados baixos, quando comparado à média de 29,6\% encontrada por Santos et al. (2009a), que também não verificaram diferença com aplicação de N. Pode-se inferir, portanto, que os valores detalhados nos estratos indicam melhor valor nutritivo para os estratos A e B e menor para o estrato C como já era esperado. Considerando que a utilização do pasto diferido normalmente é realizada no período seco sob lotação contínua, a melhor qualidade da forragem nos estratos inicialmente mais acessíveis aos animais pode sugerir manejo diferenciado durante a entrada dos animais, permitindo melhor monitoramento da qualidade do pasto e consequentemente melhor desempenho dos animais à medida que o pasto diferido é utilizado. De maneira geral os pastos diferidos possuem baixo valor nutritivo, assim, uma estratégia de manejo apropriada, segundo Paulino et al. (2006), seria a realização da suplementação do pasto, fornecendo-se os nutrientes deficientes na forragem, como forma de aumentar o consumo e o desempenho dos animais mantidos nestas pastagens.

\section{Conclusões}

A estratégia de aplicação de nitrogênio no final do verão promove maior produção de matéria seca de forragem total e de lâmina foliar nos estratos superiores do dossel, além de melhorar a qualidade da forragem. Entretanto, essa estratégia favorece a maior densidade de colmos nos estratos superiores e o elevado índice de tombamento dos pastos. Mesmo assim, a aplicação de nitrogênio no final do verão destaca-se como melhor estratégia para produção de forragem com melhor qualidade para ser utilizada no período seco. Para reduzir o tombamento de plantas, os pastos podem ser diferidos por menos tempo com essas mesmas doses de nitrogênio. O monitoramento da qualidade da forragem nos estratos verticais pode sugerir manejo diferenciado à medida que o pasto diferido é utilizado, uma vez que a utilização do pasto diferido normalmente é realizada no período seco sob lotação contínua.

\section{Referências}

ANDRADE, A.C.; FONSECA, D.M.; QUEIROZ, D.S. et al. Adubação nitrogenada e potássica em capim elefante (Pennisetum purpureum Schum. Cv. Napier). Ciência e Agrotecnologia, p.1643-1651, 2003.

CARVALHO, C.F.; GONSALVES, E.N.; POLI, C.H.E.C. et al. ecologia do pastejo. In: SIMPÓSIO SOBRE MANEJO ESTRATÉGICO DA PASTAGEM, 3., 2006, Viçosa, MG. Anais... Viçosa, MG: UFV, 2006. p.43-72.

CARVALHO, P.C.F.; GENRO, T.C.M.; GONÇALVES, E.N. et al. Estrutura do pasto como conceito de manejo: reflexos sobre consumo e a produtividade. In: SIMPÓSIO SOBRE VOLUMOSOS NA PRODUÇÃO DE RUMINANTES, 2., 2005 , Jaboticabal. Anais... Jaboticabal: FUNEP, 2005. p.107-124.

DEBEUX JÚNIOR, J.C.B.; LIRA, M.A.; FREITAS, E.V. et al. Avaliação de pastagens de braquiárias na Zona-da-Mata de Pernambuco. Revista Brasileira de Zootecnia, v.26, n.4, p.659-666, 1997.

EUCLIDES, V.P.B.; FLORES, R.; MEDEIROS, R.N. et al. Diferimento de pastos de Brachiaria cultivares Basilisk e Marandu, na região do Cerrado. Pesquisa Agropecuária Brasileira, v.42, n.2, p.273-280, 2007.

EUCLIDES, V.P.B.; THIAGO, L.R.S.; MACEDO, M.C.M. Consumo voluntário de forragem de três cultivares de Panicum maximum sob pastejo. Revista Brasileira de Zootecnia, v.28, n.6, p.1177-1185, 1999.

FAGUNDES, J.L.; FONSECA, D.M.; MISTURA, C. et al. Características morfogênicas e estruturais do capim-braquiária em pastagem adubada com nitrogênio avaliadas nas quatro estações do ano. Revista Brasileira de Zootecnia, v.35, n.1, p.21-29, 2006

GOMIDE, J.A.; GOMIDE, C.A.M. Utilização e manejo de pastagens. In: REUNIÃO ANUAL DA SOCIEDADE BRASILEIRA DE ZOOTECnIA, 38., 2001, Piracicaba. Anais... Piracicaba: Sociedade Brasileira de Zootecnia, 2001. p.808-825.

HACK, E.C.; BONA FILHO, A.; MORAES, A. et al. Características estruturais e produção de leite em pastos de capim-mombaça (Panicum maximum Jacq.) submetidos a diferentes alturas de pastejo. Ciência Rural, v.37, n.1, p.218-222, 2007.

LEMAIRE, G.; ONILLION, B.; GOSSE, G. et al. nitrogen distribution within a Lucerne canopy during regrowth: relation with light distribution. Annals of Botany, v.68, p.483-488, 1991.

MAGAlHÃES, A.F.; PIRES, A.J.V.; CARVALHO, G.G.P. et al. Influência do $\mathrm{N}$ e do fósforo na produção do capim-Brachiaria. Revista Brasileira de Zootecnia, v.36, n.5, p.1240-1246, 2007.

MARTHA JR., G.B.; VILELA, L.; BARIONI, L.G. et al. Manejo da adubação nitrogenada em pastagens. In: SIMPÓSIO SOBRE MANEJO DA PASTAGEM, 21., 2004, Piracicaba. Anais... Piracicaba: Fundação de Estudos Agrários Luiz de Queiroz, 2004. p.155-216. 
MERTENS, D.R. Análise da fibra e sua utilização na avaliação e formulação de rações. In: SIMPÓSIO INTERNACIONAL DE RUMINANTES, REUNIÃO ANUAL DA SOCIEDADE BRASILEIRA DE ZOOTECNIA, 29., 1992, Lavras. Anais... Lavras: Sociedade Brasileira de Zootecnia, 1992. p.188

MINSON, D.J. Forage in ruminant nutrition. San Diego: Academic Press, 1990. 483p

MOREIRA, L.M.; MARTUSCELLO, J.A.; FONSECA, D.M. et al. Perfilhamento, acúmulo de forragem e composição bromatológica do capim-braquiária adubado com nitrogênio. Revista Brasileira de Zootecnia, v.38, n.9, p.1675-1684, 2009.

PACIULlO, D.S.C.; AROEIRA, L.J.M.; ALVIM, M.J. et al. Características produtivas e qualitativas de pastagem de braquiária em monocultivo e consorciada com estilosantes. Pesquisa Agropecuária Brasileira, v.38, n.3, p.421-426, 2003.

PAULINO, M.F.P.; DETMANN, E.; VALADARES FILHO, S.C. Suplementação animal em pasto: energética ou protéica? In: SIMPÓSIO SOBRE MANEJO ESTRATÉGICO DA PASTAGEM, 3., 2006, Viçosa, MG. Anais... Viçosa, MG: Universidade Federal de Viçosa, 2006. p.359-392.

PRIMAVESI, A.C.; PRIMAVESI, O.; CORRÊA, L.A. et al. Adubação nitrogenada em capim-coastcross: efeitos na extração de nutrientes e recuperação aparente do nitrogênio. Revista Brasileira de Zootecnia, v.33, n.1, p.68-78, 2004.

PRIMAVESI, O.; CORRÊA, L.A.; PRIMAVESI, A.C. et al. Adubação com uréia em pastagem de Cynodon dactylon cv. Coastcross sob manejo rotacionado: eficiência e perdas. São Carlos: Embrapa Pecuária Sudeste, 2001. 42p. (Circular Técnica, 30).

PRIMAVESI, O.; PRIMAVESI, A.C.; CORRÊA, L.A. et al. Lixiviação de nitrato em pastagem de côast cross adubada com N. Revista Brasileira de Zootecnia, v.35, n.3, p.683-690, 2006.
RIBEIRO JUNIOR, J.I. Análises estatísticas no SAEG (Sistema para análises estatísticas). Viçosa, MG: UFV, 2001. 301p.

SANTOS, E.D.G.; PAULINO, M.F.; QUEIROZ, D.S. et al. Avaliação de pastagem diferida de Brachiaria decumbens Stapf. 2. Disponibilidade de forragem e desempenho animal durante a seca. Revista Brasileira de Zootecnia, v.33, n.1, p.214-224, 2004.

SANTOS, M.E.R.; FONSECA, D.M.; EUCLIDES, V.P.B. et al. Características estruturais e índice de tombamento de Brachiaria decumbens cv. Basilisk em pastagens diferidas. Revista Brasileira de Zootecnia, v.38, n.4, p.626-634, 2009a.

SANTOS, M.E.R.; FONSECA, D.M.; EUCLIDES, V.P.B. et al. Produção de bovinos em pastagens de capim-Brachiaria diferidas. Revista Brasileira de Zootecnia, v.38, n.4, p.635-642, 2009b.

SILVA, F.F.; SÁ, J.F.; SCHIO, A.R. et al. Suplementação a pasto: disponibilidade e qualidade $\mathrm{x}$ níveis de suplementação $\mathrm{x}$ desempenho. Revista Brasileira de Zootecnia, v.38, p.371-389, 2009 (supl. especial).

SILVA, S.C.; NASCIMENTO JÚNIOR, D.; EUCLIDES, V.P.B Pastagens: conceitos básicos, produção e manejo. Viçosa, MG: Suprema, 2008. 109p.

SILVA, D.; QUEIROZ, A.C. Análise de alimentos: métodos químicos e biológicos. 3.ed. Viçosa: UFV, 2002. 165p.

VITOR, C.M.T.; FONSECA, D.M.; CÓSER, A.C. et al. Produção de matéria seca e valor nutritivo de pastagem de capim elefante sob irrigação e adubação nitrogenada. Revista Brasileira de Zootecnia, v.38, n.3, p.435-442, 2009.

WOLFE, D.W.; HENDERSON, D.W.; HSIAO, T.C. et al. Interactive water and nitrogen effects on senescence of maize: I. Leaf area duration, nitrogen distribution, and yield. Agronomy Journal, v.80, p.859-864, 1988. 